\title{
Environmental performance improvement and ISO 14001: case of Lebanon
}

\author{
M. A. Massoud ${ }^{1}$, R. Tabcharani ${ }^{1}$, R. Nakkash ${ }^{2}$ \& D. Jamali ${ }^{3}$ \\ ${ }^{I}$ Department of Environmental Health, Faculty of Health Sciences, \\ American University of Beirut, Lebanon \\ ${ }^{2}$ Department of Health Promotion and Community Health, \\ Faculty of Health Sciences, American University of Beirut, Lebanon \\ ${ }^{3}$ Management, Marketing and Entrepreneurship, \\ Olayan School of Business, American University of Beirut, Lebanon
}

\begin{abstract}
This research aims to investigate the effectiveness of ISO 14001 standard in improving environmental performance and ultimately addressing the goals of sustainable environmental management. It is the first of its kind in Lebanon and adds to the existing knowledge by shedding light on a developing country where there is paucity of such studies. A multi-disciplinary research methodology combining the semi-structured interviews, documentary analysis and secondary data analysis was adopted. The findings of this research may be used to shape decisions by policy makers on the efficacy of international voluntary standards and its policy implications to economic development in general and sustainable development in Lebanon and developing countries as a whole. Consequently, industries may be more capable of justifying the expenses and efforts associated with ISO 14001 registration.
\end{abstract}

Keywords: ISO 14001, environmental performance, improvement, Lebanon.

\section{Introduction}

The ISO 14001 Environmental Management System (EMS) is a process of continuous development and improvement based on the "plan-do-check-act" cycle. It provides a plan for establishing an official and methodical EMS. It helps an organization to achieve its own objectives through clearly determining "what is going to be achieved", "who and how it is going to do it", "by when it is going 
to be achieved", and "how progress is going to be monitored" (Curkovic et al. [1]; Casadesús et al. [2]). The standard focuses on conformance with national environmental regulations in the country in which they exist. Therefore, it doesn't specify requirements for environmental performance, such as limit values on effluents discharge or emissions.

Several driving factors motivate the adoption of the ISO 14001 EMS. These motivating factors are classified into internal and external drivers (Yiridoe and Stephen [3]). The most important motivating factors vary particularly according to the type of industry and the country. For instance, Chinese organizations were primarily motivated to implement the ISO 14001 by the desire to access the international market and improve internal management (Zeng et al. [4]). The Energy and Gas organizations in Germany have sought certification with main objectives to ensure regulatory compliance, increase their operations efficiency, and improve documentation (Morrow and Rondinelli [5]). Despite the stimulating factors to implement the ISO 14001, several barriers and obstacles face organizations and hinder them from acquiring the certification. Other than the high cost of implementation and maintenance of the ISO 14001, the lack of governmental support and incentives along with the voluntary nature of the certification are the key barriers from adopting the standard.

Implementing ISO 14001 and acquiring the certification have led to environmental, economic, and managerial advantages. The ISO 14001 certification offers significant economic benefits to multinational adopting organizations, such as operational efficiency, worldwide recognition of product/brand, marketing advantages, enhanced competitiveness, and better waste management resulting in cost reduction (Curkovic et al. [1]; Studer et al. [6]). Moreover, considerable improvement of the organization's environmental performance and management efficiency are recognized among certified organizations. Such improvements include but are not limited to consistency of environmental management procedures, consumption reduction, resources savings and obvious improvements in cleaner production (Zeng et al. [4]).

In today's worldwide economy, export markets are becoming more competitive and inquiring to meet many obligatory international standards, strict environmental regulations, and high consumers' expectations concerning environmental issues. Lebanese manufacturing industries are compelled to integrate environmental standards, mainly the ISO 14001 certification, into their industry operations and systems in order to enter and compete in the international market (Massoud et al. [7, 8]). Skepticism surrounds the worthiness of the ISO 14001 in environmental protection and environmental performance improvement, as it basically sets a framework without stringent measures. Moreover, the standard's flexibility and the fact that it lacks guidelines on ensuring compliance with legal and regulatory requirements raise a question whether such a voluntary management system does or does not reduce pollution. Accordingly, this research study aims to investigate the effectiveness of ISO 14001 standard in improving environmental performance taking Lebanon as a case study. 


\section{Methodology}

An interview guide was formulated including open ended questions. Topics were selected according to the literature review of the ISO 14001. The interview guide helped focus the interview without locking it into a fixed set of questions in a rigid order and with specific wording. The interview starts with general and close-ended questions and later on (middle and end) the interviewer moves to the sensitive, controversial open-ended questions. Leading questions that might influence respondents' answers were carefully avoided. The interview was conducted in Arabic and both recording devices and note taking were used to be able to document everything.

A total number of 6 distinct Lebanese industrial organizations were identified, with their names and contact information. Of the total 6 Lebanese industrial organizations contacted, all responded, where a semi structured in-depth live interview was conducted with each one, which is equivalent to $100 \%$ response rate. Before the interview, a literature review of each type of industry concerned was conducted so as to understand the main environmental impacts of every manufacturing type. Data Analysis started by combining all notes and recordings acquired. Then, data was coded in relation to themes where it was processed and analyzed comprehensively.

\section{Results and discussion}

The six interviewed industries are constituted of two cement industries, one confectionery industry, one cosmetics industry, one pharmaceuticals industry and one transformers industry. All the interviewed industries market their products locally. A total of five industries export to regional markets and 2 out of 6 export to international ones. Furthermore, the total number of employees among the 6 industries varies between 125 and 600 workers (permanent and seasonal).

Three main reasons arose to take the decision of acquiring the ISO 14001 certificate within the six Lebanese industries of which they have been asked in the interview. Two industries are part of a multinational group and it was an international request from their intercontinental headquarters. As for three other industries, they wanted to be an example in saving the environment and this perception was already within their company planning. To overcome export barriers is the main driver of one industry who relies mainly on the international market. The interviews showed the industries' interests in the ISO 14001 certification, each depending on their establishment status and product market.

The Lebanese industries were asked what they intend to do regarding the upgrade of the ISO 14001 certification when needed, knowing that every 3 years the certificate should be updated. All the interviewed industries responded positively to that, saying that certainly they are determined to upgrade the certificate whenever required, but each with a different driver. It is quite logical to perform updates of the certification given that the ISO 14001 system has been integrated within the organization's scheme already. The most costly is the first 
time implementation of the certificate, and whenever this is done and in compliance, it is less demanding and it is a very rational decision to upgrade the certificate.

The six certified industries were asked what were/are each industry's major environmental issues and how the ISO 14001 implementation and certification enhanced the organization's environmental performance. After acquiring the ISO 14001 certification and implementing it into the organization's system, every industry has noticed positive change in the organization's environmental performance, according to the environmental issues identified.

The certified Lebanese industries are in compliance with the Lebanese environmental regulations, especially Law 444-2002 and Decision 8/1-2001 of the Ministry of Environment. The law sets the fundamental principles that would manage the use of the environment. The Ministry of Environment (MoE) also issued standard limits to air, water, and wastewater pollution from industrial sectors. Decision 8/1 published in 2001 by the MoE on the National Standards for Environmental Quality (NSEQ), covers air and liquid emissions limits of all sectors (Djoundourian [9]). The certified industries all comply with the Lebanese regulations and meet the limits of air and water effluents according to the ministerial decision 8/1-2001 and law 444.

Implementing ISO 14001 and acquiring the certification among the Lebanese manufacturing industries have led to non-environmental advantages. The most relevant benefits identified by the 6 respondents are:

- Influential marketing tool/Market expansion

- Financial profitability (directly and indirectly)

- Improved staff awareness and management development

- Enhanced corporate image

- Health and safety improvements among staff

- Better relation with stakeholders

\section{Conclusion and recommendations}

The aforementioned outcomes reported by the certified Lebanese industries show satisfactory commitments to the environment and compliance with the Lebanese environmental regulations. Further advanced actions could be considered, such as employing cleaner production options and best practices to prevent and limit consumption of resources and waste generation, in preference to performing end of pipe treatments. Also, operating energy generation and consumption using renewable energy techniques, such as PVC, wind power options and solar energy alternatives should be genuinely considered.

\section{Acknowledgement}

Special thanks are extended to the American University of Beirut Research Board for funding this research project. 


\section{References}

[1] Curkovic, S., Sroufe, R., Melnyk, S. Identifying the factors which affect the decision to attain ISO 14000. Journal of Energy, 30, 1387-1407, 2005.

[2] Casadesús, M., Marimon, F., and Heras, I. ISO 14001 diffusion after the success of the ISO 9001 model. Journal of Cleaner Production, 1-14, 2007.

[3] Yiridoe, J., Stephen C. ISO 14001 EMS standard registration decisions among Canadian organizations. Agribusiness, Vol. 19 (4) 439-457, 2003.

[4] Zeng, S., Tam, C., Deng, Z. Towards implementation of ISO 14001 environmental management systems in selected industries in China. Journal of Cleaner Production, 13, 645-656, 2005.

[5] Morrow, D., Rondinelli, D. Adopting corporate environmental management systems: Motivations and results of ISO 14001 and EMAS Certification. European Management Journal, Vol. 20, No. 2, pp. 159-171, 2002.

[6] Studer, S., Welford, R., and Hills, P. Engaging Hong Kong businesses in environmental change: Drivers and barriers. Business Strategy and the Environment, 15, 416-431, 2006.

[7] Massoud, M. A, Fayad, R. and Kamleh, R. Environmental Management System (ISO 14001) certification in developing countries: Challenges and implementation strategies. Environmental Science and Technology, 44 1884-1887, 2010a.

[8] Massoud, M. A, Fayad, R. and Mutasem, F. Drivers, barriers and incentives to implementing environmental management systems in the food industry: A case of Lebanon. Journal of Cleaner Production, 18 200-209, 2010b.

[9] Djoundourian, S. The Role of Development in Promoting Environmental Awareness: Evidence from Lebanon. Paper prepared for the 27th Annual Meeting of the Middle East Economic Association January 2007 Chicago, Illinois, 2007. 